\title{
RANCANG BANGUN ALAT MIXER VERTIKAL ADONAN KUE DONAT DENGAN GEARBOX TIPE BEVEL GEAR KAPASITAS 7 KILOGRAM
}

\author{
Fadwah Maghfurah ${ }^{1}$, Hendro Purwono ${ }^{2}$, Windarta ${ }^{3}$ \\ Jurusan Teknik Mesin, Universitas Muhammadiyah Jakarta, ${ }^{1,23}$ \\ Jl. Cempaka Putih Tengah, Cempaka Putih Tomiur, Jakarta - Pusat, 10510 ,DKI Jakarta \\ Email :fmaghfurah@yahoo.com,fadwah.maghfurah@umj.ac.id
}

\begin{abstract}
Making doughnut in a small-scale industry generally has a problem with inappropriate equipment and easy to be broken like using hand mixer. In its gearbox, the cylindrical worm gear usually made of plastic so that will easy to worn. With the use gearbox type bevel gear made of metal, then the mixer would able to overcome the problem of dough mixing where the gearbox of this type can overcome the large load with high rotation, so that the capacity of the mixer can be enlarged so that it will increase the results of work productivity. The design method begins with observation of the impact of performance, efficiency, needs and ergonomics and then proceed with the design concept of the tool design, calculation of the construction of the tool and its components and the last phase is testing of the tool by trial and error. Calculations were made to the components that will be assembling such as axis, pegs, bearings, bevel gear and its gear ratio, then the construction framework of the mixer and the container for the dough to be stirred. From the calculation results obtained from the capacity of the hand mixer with the use of $7 \mathrm{~kg} / \mathrm{hour}$, the bevel gear mixer can improve productivity results with a larger capacity of $18 \mathrm{~kg} / \mathrm{hour}$ or increased by $225 \%$ compared to hand mixer capacity.
\end{abstract}

Keywords : Mixer, Gearbox, Bevel Gear, Capacity.

\section{PENDAHULUAN}

Mixer atau pengadukan merupakan suatu aktivitas operasi pencampuran dua atau lebih zat agar diperoleh hasil campuran yang homogen. Pada media fase cair, pengadukan di tujukan untuk memperoleh keadaan yang turbulen (bergolak). Pencampuran dapat terjadi dengan cara menimbulkan gerak di dalam bahan itu yang menyebabkan bagian bagian bahan saling bergerak satu terhadap yang lainnya, sehingga operasi pengadukan hanyalah salah satu cara untuk operasi pencampuran.

Dengan penggunaan alat hand mixer maka pada proses pengadukan adonan tersebut tidak dapat digunakan pada kapasitas wadah yang besar dan sulitnya saat pengadukan pada saat adonan kue donat mulai padat, disebabkan karena pada jenis alat hand mixer umumnya yaitu menggunakan jenis gear box yang dipakai adalah jenis roda gigi cacing silindris dan menggunakan material plastik sehingga alat hand mixer akan rawan mengalami kerusakan yang disebabkan terjadinya keausan pada mata gigi tersebut.

Maka masalah tersebut dapat diatasi dengan penggunaan gear box dengan tipe bevel gear dengan material logam karena gear box jenis ini dapat mengatasi beban besar dan putaran tinggi, dan dengan mixer menggunakan gear box tipe bevel gear ini kapasitas wadah dapat diperbesar sehingga akan meningkatkan hasil produktivitas kerja.

\section{METODE PENELITIAN}

Metode yang dilakukan disini adalah metode modeling dengan membuat konsep rancang bangun alat terlebih dahulu sesuai kebutuhan setelah itu dilakukan perhitungan elemen mesin diantaranya perhitungan perencanaan poros, pasak, bantalan (bearing), bevel gear beserta ratio gear nya, rangka, dan wadah pengaduk. 


\section{HASIL DAN PEMBAHASAN 3.1. Perencanaan Perhitungan}

Poros dalam pembuatan alat mixer ini daya dan putaran motor yang telah diketahui berdasarkan spesifikasi motor adalah sebagai berikut :

$P=0,5 \mathrm{HP}=0,3675 \mathrm{~kW}$

$n_{1}=1400 \mathrm{rpm}$

Perhitungan daya rencana adalah sebagai berikut :

$\mathrm{P}_{\mathrm{d}}=\mathrm{P} \times f_{\mathrm{c}}$

$\mathrm{P}_{\mathrm{d}}=0,3675 \times 1,5=0,55125 \mathrm{~kW}$.

Perhitungan momen rencana adalah sebagai berikut :

$\mathrm{T}=9,74 \times 10^{5} \frac{P d}{n 1}$

$\mathrm{T}=9,74 \times 10^{5} \frac{0,55125}{1400}$

$\mathrm{T}=383,51 \mathrm{~kg} \cdot \mathrm{mm}$

$\mathrm{T}=3,758398$ N.m.

Bahan poros yang akan digunakan dalam perancangan ini adalah S45C (lihat pada tabel 1). Perhitungan tegangan geser yang diizinkan dengan menggunakan persamaan pada rumus di bawah ini, sebagai berikut :

$\tau_{\alpha}=\sigma_{\mathrm{B}} /(\mathrm{S} f 1 \times \mathrm{S} f 2)$

$\tau_{\alpha}=58 /(6,0 \times 3,0)$

$\tau_{\alpha}=3,22 \mathrm{~kg} . \mathrm{mm}^{2}=0,000031556 \mathrm{~N} . \mathrm{m}^{2}$.

Maka, diameter poros di dapat dengan :

$d_{s}=\left[\frac{5,1}{\tau_{\alpha}} K_{t} C_{b} T\right]^{1 / 3}$.

$d_{s}=\left[\frac{5,1}{3,22} 2,3 \times 3,0 \times 383,51\right]^{1 / 3}$

$=16,123 \mathrm{~mm}$.
Poros yang digunakan adalah $20 \mathrm{~mm}$ dengan poros yang sudah ada dipasaran.

Pasak Gaya tangensial dengan rumus :

$\mathrm{F}=\frac{\mathrm{T}}{\left(\frac{\mathrm{d}_{\mathrm{g}}}{2}\right)}$

$\mathrm{F}=\frac{383,51}{(20 / 2)}=38,351 \mathrm{~kg}=377,7998 \mathrm{~N}$.

Penampang pasak yang direncanakan menggunakan persamaan pada rumus di bawah ini, yaitu $6 \times 5(\mathrm{~mm})$. Tegangan geser yang diizinkan adalah :

$\tau_{k a}=\frac{\sigma_{B}}{S f_{k 1} \times S f_{k 2}}$

$\tau_{k a}=\frac{58}{6 \times 5}=1,94 \mathrm{~kg} / \mathrm{mm}^{2}$

$\tau_{k a}=0,000019012 \mathrm{~N} / \mathrm{m}^{2}$.

Kemanan pasak dapat dihitung dengan

$b / d_{s}=0,25<$ hasil $<0,35$

$b / d_{s}=6 / 20=0,3 ; 0,25<0,3<0,35$.

\subsection{Bantalan (Bearing)}

Alat mixer ini menggunakan bantalan gelinding yang ada dipasaran dengan nomor bantalan 6204zz dengan diameter dalam 20 $\mathrm{mm}$, diameter luar $47 \mathrm{~mm}$ dan lebar $14 \mathrm{~mm}$. Umur bantalan sebagai berikut :

$L_{h}=500 f_{h}^{3}$

$L_{h}=500 \times 2870^{3}=1.181 .995 \mathrm{jam}$.

\subsection{Bevel Gear}

Jumlah mata gigi yang penulis gunakan pada roda gigi penggerak berjumlah 10 gigi dan 16 gigi pada roda gigi yang digerakkan. Maka perbandingan roda gigi (gear ratio) dihitung dengan $z_{2} / z_{1}=i$. Kecepatan keliling dengan rumus : 
$v=\frac{\pi \times d_{1} \times n}{60 \times 1000}$

$v=\frac{3,14 \times 137,79 \times 1400}{60 \times 1000}=10,09 \mathrm{~m} / \mathrm{s}$.

Gaya Tangensial :

$F_{t}=\frac{102 \times P_{d}}{v}$

$F_{t}=\frac{102 \times 0,441}{10,09}=4,46 \mathrm{~kg}=43,798 \mathrm{~N}$.

Keamanan pada roda gigi dengan $d / m=$ hasil $<10$. Dan dari hasil didapatkan $20 / 5,08=3,93<10$, karena nilai 3,93 kurang dari 10 maka hasilnya adalah aman.

Rangka beban yang telah ditimbang pada cover beserta gear nya didapat beban sebesar $25 \mathrm{~kg}$. Beban sebesar $25 \mathrm{~kg} \times 9,8 \mathrm{~m} / \mathrm{s}^{2}=245 \mathrm{~N}$ terpusat pada penampang yang panjangnya $180 \mathrm{~mm}=0,18$ $\mathrm{m}$. Dalam rancang bangun alat mixer ini, rangka yang digunakan adalah hollow $40 \times 40 \mathrm{~mm}$ yang memiliki modulus elastisitas $E=200 \times 10^{9} \mathrm{~N} / \mathrm{m}^{2}$.

Momen Inersia dihitung dengan rumus :

$I=\frac{T \cdot H^{3}}{12}$

$I=\frac{40 \times 38,8^{3}}{12}=194703,58 \mathrm{~mm}^{3}$.
Penampang rangka pada hollow mengalami defleksi pembebanan terpusat dapat dihitung dengan rumus :

$\operatorname{Ymax}=\frac{-W L}{3 E I}$

$\operatorname{Ymax}=\frac{-245 \times 0,18^{8}}{3\left(200 \times 10^{9}\right)\left(1,9470358 \times 10^{-4}\right)}$

Ymax $=1,223 \times 10^{-8} \mathrm{~m}$.

Dari hasil perhitungan diatas, nilai defleksi pada kerangka adalah $1,223 \times 10^{-8} \mathrm{~m}$. Karena nilai $1,223 \times 10^{-8} m<1$, maka hasilnya adalah aman.

\subsection{Wadah Pengaduk}

Wadah pengaduk adonan yang penulis gunakan dalam rancang bangun alat ini memiliki ukuran diameter $300 \mathrm{~mm}$ dan tinggi $270 \mathrm{~mm}$. Volumenya dapat dihitung dengan rumus :

$V=\pi r^{2} t$

$V=3,14 \times 150^{2} \times 270$

$V=19075500 \mathrm{~mm}^{3}=19,0755 \mathrm{dm}^{3}=19,0755$ liter.

Dengan hasil 19,0755 liter, maka kapasitas wadah pengaduk adonan dapat memuat sekitar $15,2604 \mathrm{~kg}$ atau $15 \mathrm{~kg}$. Namun dalam penggunaan untuk pengadukan adonan hanya dipakai setengah dari kapasitas wadah, yaitu $7 \mathrm{~kg}$.

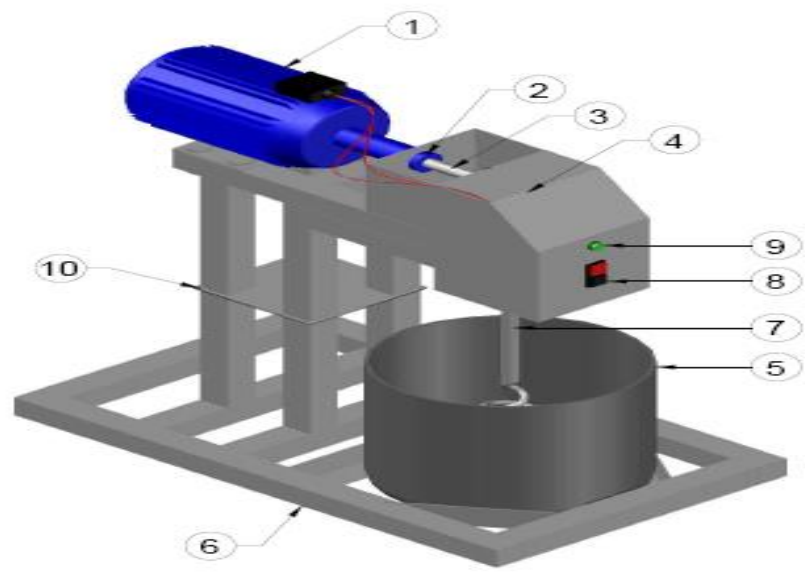

KETERANGAN

1. Motor listrik

2. Bantalan

3. Poros

4. Gearbox bevel gear

5. Wadah

7. Batang spiral

8 Tombol On/Off

9. Lampu stand by

10. Engsel

Gambar 1. Desain Mixer Bevel Gear. 


\subsection{Break Even Point}

Tabel 1. Harga Komponen

\begin{tabular}{clccc}
\hline No & \multicolumn{1}{c}{ Komponen } & Harga (Rp) & Jml & $\begin{array}{c}\text { Total } \\
\text { Harga1(Rp) }\end{array}$ \\
\hline 1 & Motor Listrik 0,5 HP & 700.000 & 1 & 700.000 \\
2 & Bevel Gear & 325.000 & 2 & 659.000 \\
3 & Poros ф 20 mm & 300.000 & 1 & 300.000 \\
4 & Bearing & 20.000 & 4 & 100.000 \\
5 & Plat Besi 10 mm & 550.000 & 1 & 550.000 \\
6 & Hollow 40 x 40 1,2 mm & 300.000 & 1 & 300.000 \\
7 & Wadah Stainless Stell & 170.000 & 1 & 170.000 \\
8 & Push Botton ON / OFF & 50.000 & 1 & 50.000 \\
9 & Kopling & 50.000 & 1 & 50.000 \\
10 & Lampu Standby & 20.000 & 1 & 20.000 \\
11 & Kabel & 20.000 & 1 & 20.000 \\
12 & Baut & 5.000 & 4 & 20.000 \\
13 & Mur & 5.000 & 4 & 20.000 \\
14 & Cat Semprot & 25.000 & 2 & 50.000 \\
\hline
\end{tabular}

Tabel 2. Fixed Cost (Biaya Tetap)

\begin{tabular}{ccc}
\hline No & Biaya Tetap & Jumlah (Rp) \\
\hline 1 & Bayar Listrik & 800.000 \\
2 & Sewa Ruko / bulan & 1.000 .000 \\
3 & Sewa Pick up / bulan & 1.500 .000 \\
\hline & TOTAL & $\mathbf{3 . 3 0 0 . 0 0 0}$ \\
\hline
\end{tabular}

Tabel 3. Variable Cost (Biaya Variabel)

\begin{tabular}{ccc}
\hline No & Biaya Variabel & Jumlah (Rp) \\
\hline 1 & Gaji Karyawan & 2.000 .000 \\
2 & Biaya Kurir & 1.00 .000 \\
\hline & TOTAL & $\mathbf{2 . 1 0 0 . 0 0 0}$ \\
\hline
\end{tabular}

Hasil Output Adonan Kue Donat

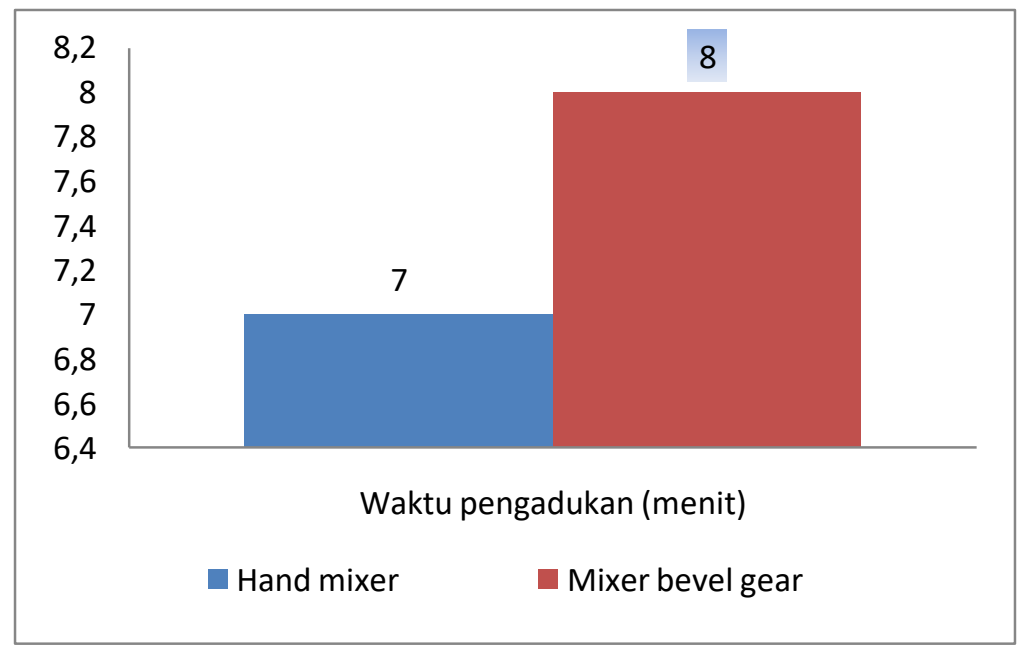

Gambar 2. Diagram Waktu Pengadukan dan Pemasukan Adonan Pada Mixer. 
Pada diagram diatas adalah waktu pengadukan (menit) dan hasil output $(\mathrm{kg} /$ jam) perbandingan antara hand mixer dan mixer bevel gear. Proses pengadukan pada mixer bevel gear dibutuhkan waktu lebih lama dikarenakan kapasitas yang lebih yang lebih besar disbanding dengan wadah pengaduk pada hand mixer.

Namun, hasil output dari mixer bevel gear menghasilkan yang lebih besar yaitu 26 $\mathrm{kg}$ / jam (Gambar 3).

$$
\begin{aligned}
& \text { BEP rupiah }=\frac{\text { biaya tetap }}{1-\left(\frac{\text { biaya variabel }}{\text { harga jual }}\right)} \\
& =\frac{3.300 .000}{1-\left(\frac{2.100 .000}{3.000 .000}\right)}=11.000 .000 .
\end{aligned}
$$

$$
\begin{aligned}
& \text { BEP unit }=\frac{\text { BE Produk }}{\text { Harga penjualan }} \\
& =\frac{11.000 .00 . . . . . .(15)}{3.000 .000}==3,66 \text { unit } \approx 4 \text { unit. }
\end{aligned}
$$

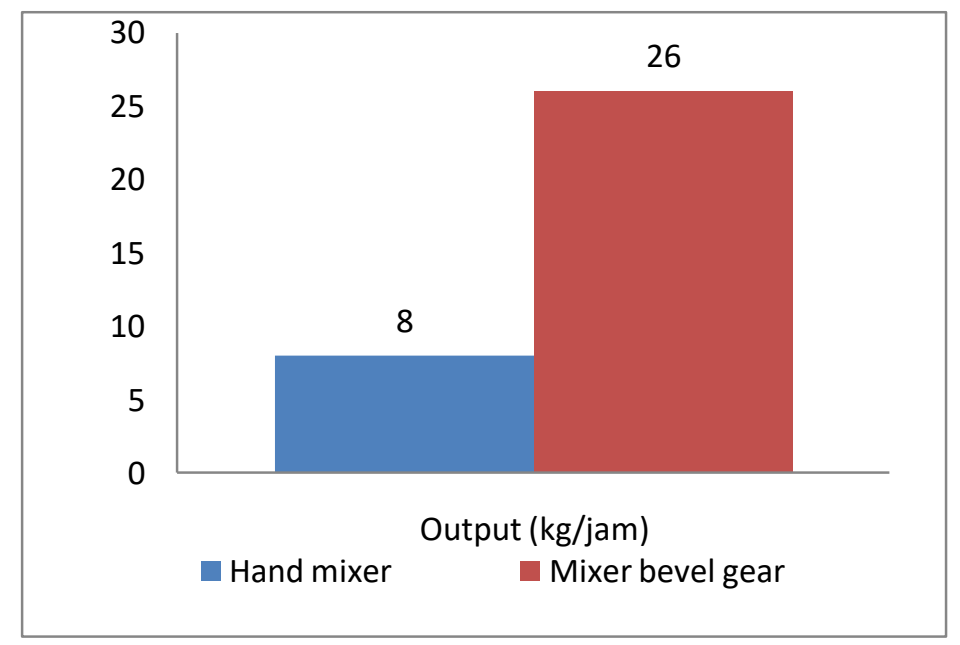

Gambar 3. Diagram Output (kg / jam) Mixer.

\section{KESIMPULAN DAN SARAN}

\subsection{Kesimpulan}

Rancang bangun alat mixer vertical adonan kue donat dengan gear box tipe bevel gear kapasitas $7 \mathrm{~kg}$ menggunakan motor listrik dengan daya sebesar 0,5 HP dengan putaran motor 1400 rpm. Gearbox yang digunakan pada rancang bangun mixer ini adalah jenis roda gigi kerucut lurus (bevel gear) dengan perbandingan roda gigi (gear ratio) adalah 1,6 sehingga putaran output yang dihasilkan setelah di reduksiya itu sebesar 875 rpm. Alatmixer ini menggunakan wadah yang dapat memuat kapasitas $7 \mathrm{~kg}$, sehingga dapat menghasilkan output sebesar $26 \mathrm{~kg} / \mathrm{jam}$.

Dengan hasil output dari hand mixer yang hanya $8 \mathrm{~kg} /$ jam, maka alat mixer bevel gear dapat meningkatkan hasil produktivitas dengan output lebih besar $18 \mathrm{~kg} /$ jam atau meningkat $225 \%$ dari kapasitas hand mixer.

\subsection{Saran}

1. Untuk perawatan pada mixer bevel gear diperlukannya perawatan pada roda gigi dengan pelumasan menggunakan gemuk (grease).

2. Penggunaan roda gigi kerucut lurus (bevel gear), dengan karakterisitik kuat pada putaran tinggi dan beban besar namun memiliki kekuranganya itu berisik pada saat beroperasi. Masalah ini dapat dilakukan peningkatan perubahan roda gigi dengan penggunaan roda gigi kerucut spiral dengan profil gigi miring yang mampu mengurangi suara berisik saat beroperasi.

3. Dengan mata pengaduk yang dapat di bongkar pasang, maka dapat dipasang dengan mata pengaduk jenis lain untuk pengadukan yang diperlukan sesuai dengan kebutuhannya. 
4. Untuk bagian wadah pengaduk dapat diberikan pengaman tambahan berupa penutup setengah lingkaran, agar menghindari risiko pada anak kecil apabila menyentuh batang pengaduk spiral saat sedang berputar.

5. Apabila ingin meningkatkan kapasitas lebih besar, dapat meningkatkan daya pada motor listrik dengan daya yang lebih besar dari 0,5 HP.

\section{DAFTAR PUSTAKA}

Ardiansyah, R., Hasanah, R. N., \& Wijono. 2013. Perancangan dan Pembuatan Alat Pengaduk Adonan Dodol dengan Kecepatan Konstan dan Torsi Adaptif, 1(4), 1-6.

Ichwanudin, N., M.Arifin, \& Wardoyo. 2011. Rancang Bangun Alat Mixer Roti Bandung Dengan Variasi Percepatan.

L.Mott, R. 2009. Elemen-elemen Mesin Dalam Perancangan Mekanis. (D. Prabantini, Ed.) (1st ed.). Yogyakarta: Andi Yogyakarta.

Prabowo, \& Seno, K. 2013. Perancangan Mesin Mixer Pengadon Kue Bolu Guna Meningkatkan Produktivitas.

Schey, J. A. 2009. Proses Manufaktur. Yogyakarta: Andi Yogyakarta.

Sri, W., \& Rusiyanto. 2010. Penerapan Adsorpsi dan Modifikasi Mixer Untuk Meningkatkan Kualitas Produk Industri Kecil Kecap. Rekayasa, (Vol 8, No 1 (2010)). Retrieved from http://journal.unnes.ac.id/nju/index. php/rekayasa/article/view/308

Subiyono, \& Karyono, S. 2011. Pengaduk Adonan Untuk Pengrajin Seni Fiberglass, 15(2), 172-181.

Sularso, \& Suga, K. 2008. Dasar Perencanaan dan Pemilihan Elemen Mesin. Jakarta: PT Pradnya Paramita.
Suyadi, S., \& Rachman, F. N. 2014. Rancang Bangun Mesin Pembuat Es Puter Dengan Pengaduk dan Penggerak Motor Listrik, 9, 41-46.

Tiwan. 2010. Rancang Bangun Mesin Pengaduk Adonan Bahan Dodol Batang dan Buah Pepaya Untuk Meningkatkan Kapasitas Produksi Industri Kecil di Pedesaan, 14, 1124. 